\title{
A Scramjet Engine Model Including Effects of Precombustion Shocks and Dissociation
}

\author{
Sean M. Torrez ${ }^{1+}$, Nathan A. Scholten ${ }^{1+}$, Daniel J. Micka ${ }^{1+}$, James F Driscoll ${ }^{1 x}$, \\ Michael A. Bolender ${ }^{2 \#}$, David B. Doman ${ }^{2 \dagger}$, Michael W. Oppenheimer ${ }^{2}$ * \\ ${ }^{1}$ Dept. of Aerospace Engineering, University of Michigan, Ann Arbor MI 48109 \\ ${ }^{2}$ Air Force Research Laboratory AFRL/RB, WPAFB, OH 45433-7531
}

\begin{abstract}
A new scramjet engine model has been developed to support hypersonic vehicle design studies and flight dynamics and control system analysis. This paper explains the methodology and the governing equations for the new propulsion system model that is suitable for use with a control oriented dynamic model of a hypersonic vehicle. Previous propulsion models used for this purpose were based on simple Rayleigh flow for the combustion process, but despite this, captured the propulsion system interactions with the vehicle aerodynamics and structural dynamics. A new, higher fidelity propulsion system model is constructed that simulates numerous phenomena that were neglected in the Rayleigh flow approach. The new model is of higher fidelity, and therefore it is not designed to calculate the flow physics on a timescale that is suitable for dynamics and control simulations. Instead it will be used as a truth model and the starting point for the derivation of a reduced-order model. Specific phenomena that are included in the new model are: a pre-combustion shock train within the isolator and its interactions with the combustor, the loss of stagnation pressure due to gas dissociation and recombination, wall heat transfer and skin friction, a fuel-air mixing submodel, and a finite-rate chemistry and autoignition reaction mechanism. It is shown that the new propulsion system model expands the operability envelope as compared to the previous model by accommodating ramjet combustion, which occurs at high supersonic/low hypersonic flight Mach numbers.
\end{abstract}

+ Research Assistant, Student Member, AIAA

$x$ Professor of Aerospace Engineering, Fellow, AIAA

\# Aerospace Engineer. Senior Member, AIAA.

$\dagger$ Senior Aerospace Engineer. Associate Fellow, AIAA

* Electronics Engineer, Member, AIAA 


\section{Nomenclature}

$\mathrm{A}=$ engine duct area

$\mathrm{c}_{\mathrm{p}}=$ heat capacity

$\mathrm{C}_{\mathrm{f}}=$ friction coefficient

$\mathrm{C}=$ concentration $(\mathrm{mol} / \mathrm{cc})$

$\mathrm{d}=$ fuel injector diameter

$\mathrm{D}=$ engine hydraulic diameter

$\mathrm{f}=$ fuel jet mixture fraction

$\mathrm{h}_{\mathrm{i}}=$ enthalpy/mass, species I

$\mathrm{h}_{\mathrm{fi}}^{\mathrm{o}}=$ heat of formation/mass

$\mathrm{h}_{0, \mathrm{~s}}=$ total sensible enthalpy

$\mathrm{h}_{\mathrm{RP}}=$ heat of reaction/mass

$\mathrm{k}_{\mathrm{f}}=$ reaction rate coefficient

$\mathrm{L}_{\mathrm{m}}=$ mixing length

$\mathrm{M}=$ Mach number

$\mathrm{m}=$ total mass $/ \mathrm{sec}$

$\mathrm{m}_{\mathrm{i}, \text { added }}=$ mass $/ \mathrm{sec}$ added

$\mathrm{MW}=$ molecular weight $\mathrm{p}=$ static pressure

$\mathrm{p}_{0}=$ stagnation pressure

$\mathrm{Pr}=$ Prandtl number

$\mathrm{P}_{\mathrm{W}}=$ duct perimeter

$\mathrm{Q}=$ combustion $\mathrm{kJ} / \mathrm{sec}$

$\mathrm{r}=$ radial distance

$\mathrm{R}=$ fuel jet radius

$\mathrm{R}_{\mathrm{u}}=$ gas constant

$\mathrm{T}=$ static temperature

$\mathrm{T}_{0}=$ stagnation temp

$\mathrm{T}_{\mathrm{aw}}=$ adiabatic wall temp

$\mathrm{T}_{\mathrm{w}}=$ wall temperature

$\mathrm{U}=$ gas velocity

$\mathrm{x}=$ streamwise distance

$X_{i}=$ mole fraction $i^{\text {th }}$ species

$Y_{i}=$ mass fraction $i^{\text {th }}$ species
Greek symbols

$\alpha=$ vehicle angle of attack

$\beta=$ bow shock angle

$\varepsilon=$ fuel direction parameter

$\gamma=$ ratio of specific heats

$\phi=$ fuel-air equivalence ratio

$\rho=$ gas density

$\xi=$ normalized jet concentration

$\dot{\omega}_{i}=$ volumetric reaction rate

\section{$\underline{\text { Subscripts }}$}

$\mathrm{A}=$ air

$\mathrm{c}=$ fuel jet centerline

$\mathrm{F}=$ fuel

$\mathrm{NP}=$ no pre-combustion shock

$\mathrm{R}=$ rich flammability limit

$\mathrm{s}=$ stoichiometric

$\infty=$ free stream

\section{Introduction}

Recently there have been efforts to develop a model [1] of a generic air-breathing hypersonic vehicle that is based on first principles; the vehicle is shown in in Figure 1. The purpose of these efforts has been to develop a modeling environment that can be used by both aircraft conceptual designers and flight dynamics and control engineers to help understand the physical manifestation of the complex interactions between the aerothermodynamics, propulsion system, control system, and structural dynamics that are expected to occur in full-scale scramjet-powered hypersonic vehicle configurations. Such a modeling environment will allow flight control engineers to obtain a fundamental understanding of the effects of these interactions on the open-loop dynamics of the system, and enable rapid exploration of the configuration design-space to enhance the controllability of the vehicle.

For example, the vehicle configuration might be modified by the addition of a new control effector or by making a change to the outer mold line that results in improved controllability. The philosophy of this modeling effort is such that the aerodynamics forces and moments are not stored in look-up tables, but instead are calculated at each time step of a simulation, given the actuation of the controls and the current

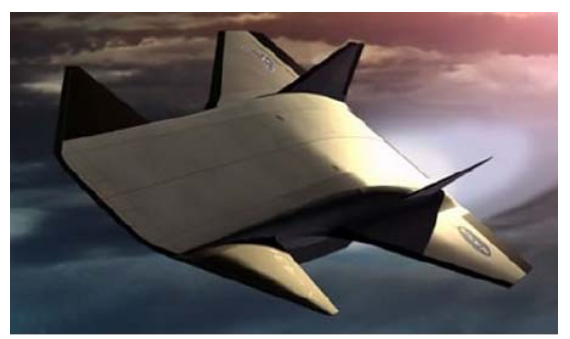

Figure 1. Artist's Concept of an Air-breathing Hypersonic Vehicle

state of the vehicle. In the original vehicle model [1] it was assumed that the airflow over the vehicle was 2$\mathrm{D}$, inviscid and quasi-steady. This assumption allowed the use oblique-shock theory and Prandtl-Meyer flow to determine the pressure distribution on the vehicle. However, a drawback of this approach was that there was no means by which one could calculate the aerodynamic damping derivatives or the unsteady 
aerodynamic forces and moments due to the vehicle flexing. Also, the aerodynamic model ignored significant viscous effects that affect the drag and pitch dynamics of such vehicles. Many other shortcomings in the original model were identified, and as a result, there has been a significant effort to incrementally add complexity and fidelity. For example, to remedy the lack of damping derivatives, linear piston theory has been utilized to capture the unsteady components of the flow field [2,3]. Because the original model assumed inviscid flow, an analytical skin friction model using Eckert's reference temperature method has been incorporated into the model [4] to give more realistic drag estimates. Additionally, changes have been made to the aeroelastic model to improve the estimation of the mode shapes and frequencies of the structural dynamics $[5,6]$. The initial structural model was limited because it could only approximate the first mode shape of the structure, and it was difficult to capture mass and temperature effects on the mode shapes of the vehicle. By utilizing the assumed modes method $[5,6]$ one may now calculate any desired number of frequencies and mode shapes for the vehicle.

The propulsion system model used in Reference [1] was the one developed by Chavez and Schmidt [7]. A similar approach was used by Tarpley and Lewis [8]. The engine flow path is shown in Figure 2. It consists of a diffuser, a constant area combustor, and a nozzle. It was assumed that the diffuser and the nozzle were perfectly isentropic, and the combustion process was modeled as a change in total temperature, which in turn was a function of the equivalence ratio. This previous model used the pressure and temperature computed downstream of the oblique shock as the engine entrance boundary conditions. For a specified equivalence ratio, mass flow is calculated as a function of angle-of-attack and Mach number to determine the thrust. While this approach gives the correct qualitative thrust relationship as a function of Mach number, altitude, angle-of-attack, and equivalence ratio, in some parts of the flight envelope the combustor thermally chokes at very low equivalence ratios, which unrealistically limits the performance of the vehicle. Therefore, the motivation behind this paper is to better estimate a thrust and engine operability over a wider range of flight conditions, including ramjet to scramjet mode transition.

The new model of the combustor section is similar to previous analyses of heat addition to a variable area duct which were originally discussed by Shapiro [9]. More recently, O'Brien, Starkey, and Lewis [10], Starkey [11], Birzer and Doolan [12], and Tetlow and Doolan [13] have constructed propulsion system models of varying fidelity to support hypersonic vehicle design studies. The present work extends the previous models by including rigorous models of the fuel-air mixing of a jet in a cross flow and the combustor-isolator interactions that determine the strength of the pre-combustion shock train. The mixing model is based on recent experiments of jets mixing in supersonic cross flows. The 18 step finite-rate chemistry mechanism of Zambon and Chelliah [14] was added to account for the use of either ethylene,

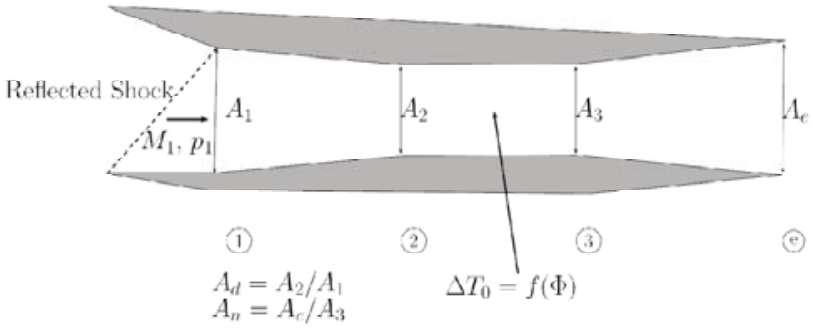

Figure 2. Engine flowpath used in Reference [1]

hydrogen or methane fuel. The finite-rate chemistry mechanism has been carefully validated in Ref. 14 for high temperature reactants that are in the autoignition regime. Gas dissociation and variable heat capacity are included to model the stagnation temperature loss that occurs due to dissociation. Some of this loss can be recovered in the nozzle provided that there is sufficient time for recombination. Wall heat transfer and skin friction effects also are included. This paper is divided into five sections that describe the combustion process, fuel-air mixing, chemical kinetics, the combustor-isolator interaction [15], and dissociation across shock waves [16]. In the section on the combustor-isolator interaction, a method is described to compute stagnation pressure losses across the pre-combustor shock train in the isolator. 


\section{Model of the Combustor Section}

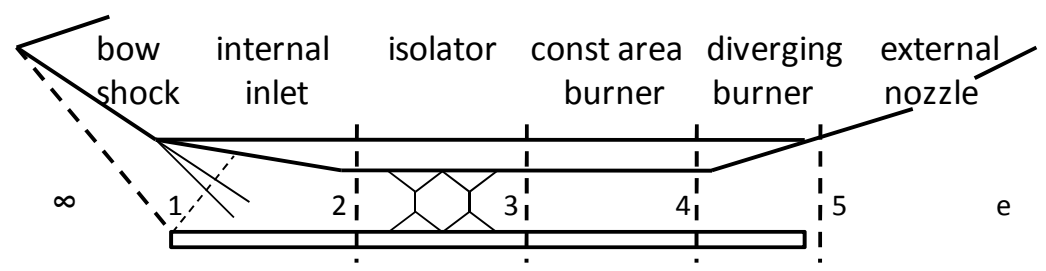

Figure 3. Schematic of Dual-Mode Scramjet Engine With Stations 1-5 Labeled.

The combustor section shown in Fig. 3 consists of two parts: a nearly constant area burner (3-4) into which the mass flow rate of fuel injected is $\dot{m}_{f, 34}$ followed by a diverging area burner (4-5) into which the fuel injected is $\dot{m}_{f, 45}$. For reasons described in Ref. 15, during ramjet operation fuel must be injected into both burners, while for scramjet operation no fuel is injected into the diverging burner. The 1-D model of the combustor is based on the following well-established conservation equations.

$$
\begin{aligned}
& \frac{1}{\rho} \frac{d \rho}{d x}=\frac{1}{\dot{m}} \frac{d \dot{m}}{d x}-\frac{1}{U} \frac{d U}{d x}-\frac{1}{A} \frac{d A}{d x} \\
& \frac{1}{U} \frac{d U}{d x}=\frac{-1}{\gamma M^{2}}\left(\frac{1}{p} \frac{d p}{d x}+\frac{2 \gamma M^{2} C_{f}}{D}+\frac{\gamma M^{2}(1-\varepsilon)}{\dot{m}} \frac{d \dot{m}}{d x}\right) \\
& \frac{1}{p} \frac{d p}{d x}=\frac{1}{\rho} \frac{d \rho}{d x}+\frac{1}{T} \frac{d T}{d x}-\frac{1}{\overline{M W}} \frac{d \overline{M W}}{d x} \\
& \frac{d \overline{M W}}{d x}=-\overline{\mathrm{MW}}^{2} \sum_{i}\left(\frac{1}{M W_{i}} \frac{d Y_{i}}{d x}\right) \\
& \frac{d \dot{m}}{d x}=\sum_{i} \frac{d \dot{m}_{i, a d d e d}}{d x} \\
& \frac{d T}{d x}=\frac{1}{\hat{c}_{p}}\left\{-\sum_{i}\left(h_{i} \frac{d Y_{i}}{d x}\right)+\left[\frac{1}{\dot{m}} \sum_{i}\left(h_{i}\left(\frac{d \dot{m}_{i, a d d e d}}{d x}\right)\right)-\frac{h_{0}}{\dot{m}} \frac{d \dot{m}}{d x}\right]-\frac{2 C_{f} c_{p}\left(T_{a w}-T_{w}\right)}{\operatorname{Pr}^{2 / 3} A}-\mathrm{U} \frac{d U}{d x}\right\} \\
& \frac{d Y_{i}}{d x}=\frac{\dot{\omega}_{i} M W_{i} A}{\dot{m}}+\frac{1}{\dot{m}} \frac{d \dot{m}_{i, a d d e d}}{d x}-\frac{Y_{i}}{\dot{m}} \frac{d \dot{m}}{d x} \\
& \dot{\omega_{i}}=\frac{d C_{Q_{i}}}{d t}=\sum_{j}\left[k_{f, j}\left(v_{\mathrm{ij}}{ }^{\prime \prime}-v_{\mathrm{ij}}^{\prime}\right) \prod_{i} C_{i}^{v^{\prime} i j}\right]
\end{aligned}
$$

Equations 1-3, 6 and 7 express the conservation of mass, momentum, energy, mass fraction $\left(\mathrm{Y}_{\mathrm{i}}\right)$ of the i-th species, and an equation of state $[9,10]$. They are written in the manner that is consistent with O'Brien et al. [10]. Equation 4 defines the molecular weight of the mixture, and Eq. 8 defines $\omega_{i}$, which is volumetric reaction rate of the i-th species (in moles $/$ second $/ \mathrm{m}^{3}$ ). The right side of Eq. 5 contains the mass per second of fluid added through the sidewalls; for all cases considered this added mass is the fuel. 
Equations 1-8 represent $(6+2 \mathrm{~N})$ equations for the $(6+2 \mathrm{~N})$ unknowns $\left(\rho, \mathrm{U}, \mathrm{p}, \overline{M W}, \mathrm{~T}, \dot{m}, \mathrm{Y}_{\mathrm{i}}\right.$ and $\left.\dot{\omega}_{i}\right) . \mathrm{N}$ is the number of species in the reacting gas mixture which is 22 . Equations 1-8 contain a number of terms that are now described. First consider the energy equation for the specific case when no fuel mass is added through the sidewalls $\left(\dot{m}_{i, \text { added }}=0\right)$ ). Refs. 8 and 9 explain that the energy equation is:

$$
\frac{d h_{0}}{d x}=-\frac{2 C_{f} c_{p}\left(T_{a w}-T_{w}\right)}{\operatorname{Pr}^{2 / 3} A}
$$

The heat transfer coefficient $\left(\mathrm{C}_{\mathrm{H}}\right)$ does not appear because the heat loss to the wall instead is written in terms of the skin friction coefficient $\mathrm{C}_{\mathrm{f}}$, which is proportional to $\mathrm{C}_{\mathrm{H}}$ because of the Reynolds analogy:

$$
C_{H}=C_{f} /\left(2 \operatorname{Pr}^{\frac{2}{3}}\right)
$$

The following equations define the stagnation enthalpy/mass $\left(\mathrm{h}_{0}\right)$, the static enthalpy/mass $(\mathrm{h})$ and the static enthalpy/mass of the $i$-th species $\left(h_{i}\right)$.

$$
\begin{gathered}
h_{0}=h+U^{2} / 2 \quad h=\sum_{i} h_{i} Y_{i} \\
h_{i}=h_{f, i}^{0}+\int_{298 K}^{T} c_{p, i} d T
\end{gathered}
$$

The heat of formation of the i-th specie is $h_{f, i}^{o}$. Inserting Eqs. 11 into Eq. 9, the left side of Eq. 9 becomes:

$$
\begin{aligned}
\frac{d h_{0}}{d x} & =\sum_{i} Y_{i} \frac{d h_{i}}{d x}+\sum_{i} h_{i} \frac{d Y_{i}}{d x}+U \frac{d U}{d x}=\sum_{i}\left(Y_{i} c_{p, i}\right) \frac{d T}{d x}+\sum_{i} h_{i} \frac{d Y_{i}}{d x}+U \frac{d U}{d x} \\
& =c_{p} \frac{d T}{d x}+\sum_{i} h_{i} \frac{d Y_{i}}{d x}+U \frac{d U}{d x}
\end{aligned}
$$

The heat capacity of the gas mixture (22 species) is defined as:

$$
c_{p}=\sum_{i} c_{p, i} Y_{i}
$$

It is seen that the final energy equation (Eq. 6) is obtained by equating Eqs. 9 and 12a for the specific case of no mass addition. The heat that is liberated by combustion is determined by the values of the heat of formation $\left(h_{f, i}^{0}\right)$ terms in Eq. 11. Similarly, when the gas dissociates (or recombines), these same heat of formation terms properly create the correct change in the stagnation temperature. When fuel mass is added through the sidewalls the two additional terms in the square brackets in Eq. 6 must be included, as explained by the derivation found in Ref. 10. Note that these two terms in square brackets in Eq. 6 sum to zero if the enthalpy/mass added by the fuel equals the enthalpy/mass of the main gas mixture, as expected. When fuel mass is added, Ref. 10 shows that the effective heat capacity of the gas mixture is slightly modified, such that the quantity:

$$
\hat{c}_{p}=c_{p}-\frac{1}{\dot{m}} \sum_{i} c_{p, i} \dot{m}_{i, a d d e d}
$$

appears on the right side of Eq. 6 . The second term on the right side of Eq. 13 is only a minor modification to the heat capacity, since the added mass flow rate is typically less than $3 \%$ of the total mass flow rate. The Mach number $M$ in Eq. 2 is defined as $U /(\gamma R T)^{1 / 2}$ and the gas constant $\mathrm{R}$ is $\mathrm{R}_{\mathrm{u}} \overline{M W}$ where $\mathrm{R}_{\mathrm{u}}$ is the universal gas constant. The quantities that must be provided to the model (as a function of the downstream coordinate $\mathrm{x}$ ) include:

a) the flow area (A),

b) the mass of the $i$-th fuel species that is added $\left(\dot{m}_{i, \text { added }}\right)$, from the mixing submodel,

c) the reaction rate of the $i$-th species $\left(\dot{\omega}_{i}\right)$, from the chemical kinetics submodel,

d) the wall skin friction coefficient $\left(\mathrm{C}_{\mathrm{f}}\right)$, and 
e) the hydraulic diameter (D) which is defined to be $\left(4 \mathrm{~A} / \mathrm{P}_{\mathrm{w}}\right) ; \mathrm{P}_{\mathrm{w}}$ is the wetted perimeter of the duct.

f) The parameter $(\varepsilon)$ is either unity or zero if the mass added is in the direction of the flow or is perpendicular to the flow, respectively.

\section{Model of the Fuel-Air Mixing}

Fuel-air mixing is an important process that affects the engine thrust; the thrust is reduced if not all of the fuel mixes in the short time that fluid elements remain in the combustor. Fuel-air mixing is characterized by the term $\left(\mathrm{d} \dot{m}_{i} / \mathrm{dx}\right)_{\text {added }}$ that appears on the right side of Eq. 5 . The quantity $\dot{m}_{i}$ in this term is the added mass/second of fuel that is molecularly mixed with the air; it is not simply the mass/second of fuel that enters the air stream. Fuel begins to become molecularly mixed at the fuel injection port, but molecularly-mixed fuel continues to be added to the air for a distance $\mathrm{L}_{\mathrm{m}}$ downstream of the fuel injection port. $\mathrm{L}_{\mathrm{m}}$ is defined to be the mixing distance required to mix the fuel and air to the rich flammability limit. After this mixing is completed, the second step in the combustion process occurs when the chemical kinetics that are associated with autoignition begin to consume the fuel.

A mixing model is required to determine $\left(\mathrm{d} \dot{m}_{i} / \mathrm{dx}\right)_{\text {added. }}$ A deficiency of many previous engine models is that they rely on outdated mixing data, and unfortunately the representation of the mixing process is often the weakest link of an entire engine model. To alleviate this potential problem, the present approach is based on modern mixing theory and on mixing data recently obtained with laser imaging diagnostics. First it is assumed that fuel is injected in a sidewall jet that is perpendicular to the supersonic air cross-stream. $\left(\mathrm{d} \dot{m}_{F} / \mathrm{dx}\right)_{\text {added }}$ is given by:

$$
\left(\frac{\mathrm{dm} \dot{\mathrm{m}}_{\mathrm{F}}}{\mathrm{dx}}\right)_{\text {added }}=\frac{\mathrm{d}}{\mathrm{dx}} \int_{\mathrm{A}^{*}} \rho U \mathrm{Y}_{\mathrm{F}} \mathrm{dA}
$$

The integral in Eq. 14 is the mass per second of fuel that passes through the area $\mathrm{A}^{*}$. We define $\mathrm{A}^{*}$ to be the grey annular region on each of the vertical planes shown in Fig. 4b. Within this annular region $A^{*}$ the value of the fuel mass fraction $Y_{F}$ lies between the rich and the lean flammability limits. Thus "mixed" fluid is defined to be fluid has a value of $\mathrm{Y}_{\mathrm{F}}$ that is in the flammable range.

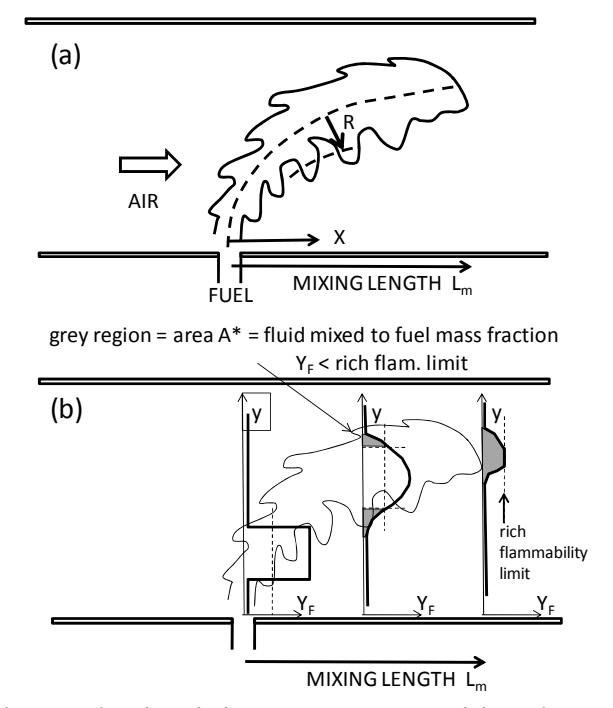

Figure 4. Schematic of the Fuel-AirMixing Process Considered. Grey region in (b) is A*; it represents area through which the fuel mass fraction $\mathrm{Y}_{\mathrm{f}}$ has been mixed to a value below the rich flammability limit.

Smith and Mungal [17] have measured the profiles of $Y_{F}$ within a jet injected into a transverse air flow, and Hasselbrink and Mungal [18] showed that there is approximate self-similarity to the scalar and velocity fields. They show that it is possible to simplify Eq. 14 to be: 


$$
\left(\frac{\mathrm{dm}}{\mathrm{dx}}\right)_{\text {added }}=\frac{\mathrm{d}}{\mathrm{dx}}\left(\mathrm{B} \rho_{\mathrm{c}} \mathrm{U}_{\mathrm{c}} \mathrm{Y}_{\mathrm{F}, \mathrm{c}} \mathrm{R}^{2}\right)
$$

The subscript $\mathrm{c}$ refers to properties on the jet centerline, which is the curved dashed line in Fig. 4a. R(x) is the radius of the jet, and it is identified in Fig. 4a. In Ref. 18 it is reported that $R$ is equal to $0.10 \mathrm{x}$. The quantity $\mathrm{B}$ is given by:

$$
\mathrm{B}=\int_{\mathrm{r}_{1} / \mathrm{R}}^{\mathrm{r}_{2} / \mathrm{R}} \frac{\rho}{\rho_{\mathrm{c}}} \frac{\mathrm{U}}{\mathrm{U}_{\mathrm{c}}} \frac{\mathrm{f}}{\mathrm{f}_{\mathrm{c}}} 2 \pi \frac{\mathrm{r}}{\mathrm{R}} \frac{\mathrm{dr}}{\mathrm{R}}
$$

The limits $r_{2}$ and $r_{1}$ correspond to locations of the rich and lean flammability limits, respectively. Measurements in Refs. 17 and 18 show that the jet flow in a transverse air stream is approximately selfsimilar, so the integrand in Eq.16 is the product of three nearly Gaussian functions of (r/R). Inserting these Gaussian functions into Eq. 16 it follows that:

$$
\mathrm{B}=\text { function }\left(\mathrm{Y}_{\mathrm{F} 2}, \mathrm{Y}_{\mathrm{F} 1}, \mathrm{Y}_{\mathrm{F}, \mathrm{c}}\right)
$$

$\mathrm{Y}_{\mathrm{F} 2}$ and $\mathrm{Y}_{\mathrm{F} 1}$ are the known fuel mass fractions at the rich and lean flammability limits, respectively. The remaining three unknowns in Eqs. 16 and 17 now are represented in terms of a single unknown: the mixture fraction along the jet centerline $\left(\mathrm{f}_{\mathrm{c}}\right)$. Mixture fraction is a conserved scalar and it is defined to be the mass fraction of hydrogen atoms, which may exist within $\mathrm{H}_{2}, \mathrm{H}_{2} \mathrm{O}, \mathrm{OH}$ or other molecules [19]. The gas density and fuel mass fraction along the jet centerline are given by mixture fraction concepts [19] to be:

$$
\begin{aligned}
\rho_{c}=\frac{p}{R_{N 2}}\left[\left(T_{A}+\Delta T-T_{F}\right)\left(\frac{1-f_{c}}{1-f_{s}}\right)+T_{F}\right]^{-1} & \text { for fuel rich conditions } \mathrm{f}_{\mathrm{c}}>\mathrm{f}_{\mathrm{s}} \\
\rho_{c}= & \frac{p}{R_{N 2}}\left[T_{A}+\Delta T \frac{f_{c}}{f_{s}}\right]^{-1} \quad \text { for fuel lean conditions } \mathrm{f}_{\mathrm{c}}<\mathrm{f}_{\mathrm{s}} \\
U_{c}=U_{F} f_{c} & \\
U_{F}= & \left(\gamma_{F} R_{F}(0.8333) T_{0 F}\right)^{1 / 2} \\
\rho_{F}= & 0.6339 p_{0 F} /\left(R_{F} T_{0 F}\right) \\
Y_{F, c}= & \frac{f_{c}-f_{s}}{1-f_{s}}
\end{aligned}
$$

The fuel port is choked, so $U_{F}$ is the sonic velocity of the fuel and $\rho_{\mathrm{F}}$ is the sonic density. The fuel stagnation pressure $\mathrm{p}_{0 \mathrm{~F}}$ and stagnation temperature $\mathrm{T}_{0 \mathrm{~F}}$ must be specified. $\mathrm{R}_{\mathrm{N} 2}$ is the gas constant for nitrogen and $\mathrm{U}_{\mathrm{F}}$ is the fuel jet velocity. $\mathrm{T}_{\mathrm{A}}$ is the static temperature of air entering the jet, $\mathrm{T}_{\mathrm{F}}$ is the initial temperature of the fuel, and $\Delta \mathrm{T}$ is the temperature increment that would be added to the air temperature by stoichiometric, $100 \%$ completed combustion. $\Delta \mathrm{T}$ is $2065 \mathrm{~K}$ for hydrogen-air reactants and is $1910 \mathrm{~K}$ for ethylene-air reactants. The stoichiometric mixture fraction $\left(\mathrm{f}_{\mathrm{s}}\right)$ is 0.029 for hydrogen-air reactants, and is 0.068 for ethylene-air reactants. To close the problem, a measured scaling relation for centerline mixture fraction $f_{c}$ is required. It is known from dimensional arguments that $f_{c}$ must depend on the parameters $\left(\mathrm{U}_{\mathrm{F}} / \mathrm{U}_{\mathrm{A}}\right),\left(\rho_{\mathrm{F}} / \rho_{\mathrm{A}}\right)$ and $(\mathrm{x} / \mathrm{d})$, where $\mathrm{U}_{\mathrm{A}}$ is the air velocity and $\mathrm{d}$ is the fuel port diameter. Planar laser induced fluorescence of acetone seeded into a nonreacting jet in a cross flow was used $[17,18]$ to measure the normalized jet fluid concentration $\left(\xi_{c}\right)$ to be:

$$
\xi_{c}=0.85\left(\frac{x}{d}\right)^{-2 / 3}\left(\frac{\rho_{F}}{\rho_{A}}\right)^{1 / 2}\left(\frac{U_{F}}{U_{A}}\right)^{-1 / 3}
$$

The relationship between mixture fraction and normalized jet fluid concentration is: 


$$
f_{c}=\frac{\xi_{c} M W_{F}}{\xi_{c} M W_{F}+\left(1-\xi_{c}\right) M W_{A}}
$$

$\mathrm{MW}_{\mathrm{F}}$ is the molecular weight of the fuel. The above set of algebraic equations (Eqs. 15-25) provide values of $\left(\mathrm{d} \dot{m}_{f} / \mathrm{dx}\right)_{\text {added }}$ as a function of $\mathrm{x}$, which is input into Eq. 5 . In addition, the equations make it possible to compute the mixing distance $\mathrm{L}_{\mathrm{m}}$, which is the distance between the fuel injector and the location where the fuel-air mixture is mixed to the rich flammability limit. To determine $\mathrm{L}_{\mathrm{m}}$ Eq. 24 is employed, $\xi_{\mathrm{c}}$ is set equal to $\xi_{\mathrm{R}}$, the fuel mole fraction at the rich flammability limit. Then $\mathrm{x}$ is set equal to $\mathrm{L}_{\mathrm{m}}$. Rearranging the resulting equation yields the following normalized mixing length (i.e., the distance required to mix the fuel to the rich flammability limit on the centerline of a jet in a transverse air flow):

$$
\frac{L_{m}}{d}=\left(\frac{0.85}{\xi_{R}}\right)^{3 / 2}\left(\frac{\rho_{F}}{\rho_{A}}\right)^{3 / 4}\left(\frac{\mathrm{U}_{F}}{\mathrm{U}_{A}}\right)^{-1 / 2}
$$

This general approach has been verified for subsonic flames [20-24] and by supersonic transverse jet mixing experiments [25-27]. Eq. 26 indicates that increasing the air velocity $\left(U_{A}\right)$ causes the flame to bend more in the air flow direction, which increases $\mathrm{L}_{\mathrm{m}}$. Increasing the fuel velocity $\mathrm{U}_{\mathrm{F}}$ sufficiently will cause the flame in Fig. 4 to be nearly vertical, so its length $\mathrm{L}_{\mathrm{m}}$ in the air flow direction will be small. I

\section{Finite-Rate Chemistry of Hydrogen, Ethylene, or Methane Fuels}

After the fuel and air have mixed to the rich flammability limit, autoignition will occur at the

temperatures that are associated with scramjet engines. If the finite-rate chemistry is too slow, not all of the fuel will burn, even though it has been molecularly mixed. The finite-rate chemistry continues throughout the exhaust nozzle, where some recombination will occur. The finite-rate chemistry enters the conservation equations due to the volumetric reaction rate $\dot{\omega}_{i}$, which is defined by Eq. 8 and appears in Eq. 7. To

\section{Chemical Reactions:}

$\begin{array}{ll}\text { I } & \mathrm{C}_{2} \mathrm{H}_{4}+\mathrm{H}=\mathrm{CH}_{3}+\mathrm{CH}_{2} \\ \text { II } & \mathrm{C}_{3} \mathrm{H}_{5}+\mathrm{H}_{2}=\mathrm{C}_{3} \mathrm{H}_{6}+\mathrm{H} \\ \text { III } & \mathrm{C}_{2} \mathrm{H}_{4}+\mathrm{CH}_{3}=\mathrm{C}_{3} \mathrm{H}_{6}+\mathrm{H} \\ \text { IV } & \mathrm{C}_{2} \mathrm{H}_{3}+\mathrm{H}_{2}=\mathrm{CH}_{3}+\mathrm{CH}_{2} \\ \text { V } & \mathrm{C}_{2} \mathrm{H}_{6}=2 \mathrm{CH}_{3} \\ \text { VI } & \mathrm{CH}_{4}=\mathrm{CH}_{3}+\mathrm{H} \\ \text { VII } & \mathrm{C}_{2} \mathrm{H}_{2}+\mathrm{H}_{2}=2 \mathrm{CH}_{2} \\ \text { VIII } & \mathrm{CH}_{3}=\mathrm{CH}_{2}+\mathrm{H} \\ \text { IX } & \mathrm{CH}_{2} \mathrm{O}+\mathrm{H}_{2}=\mathrm{CH}_{2}+\mathrm{H}_{2} \mathrm{O} \\ \text { X } & \mathrm{CH}_{2} \mathrm{CO}=\mathrm{CH}_{2}+\mathrm{CO} \\ \text { XI } & \mathrm{CO}_{2}+2 \mathrm{H}_{2}+\mathrm{O}=\mathrm{CH}_{2}+2 \mathrm{H}+\mathrm{O}_{2} \\ \text { XII } & \mathrm{CO}_{2}=\mathrm{CO}+\mathrm{O} \\ \text { XIII } & \mathrm{H}_{2} \mathrm{O}_{2}=2 \mathrm{OH} \\ \text { XIV } & \mathrm{HO}_{2}=\mathrm{O}_{2}+\mathrm{H} \\ \text { XV } & \mathrm{H}_{2}=2 \mathrm{H} \\ \text { XVI } & \mathrm{H}_{2} \mathrm{O}+\mathrm{H}=\mathrm{H}_{2}+\mathrm{OH} \\ \text { XVII } & \mathrm{H}+\mathrm{OH}=\mathrm{H}_{2}+\mathrm{O} \\ \text { XVIII } & \mathrm{O}+\mathrm{OH}=\mathrm{O}_{2}+\mathrm{H}\end{array}$

\section{Species Considered:}

$\mathrm{C}_{3} \mathrm{H}_{5}, \mathrm{C}_{3} \mathrm{H}_{6}$, $\mathrm{C}_{2} \mathrm{H}_{2}, \mathrm{C}_{2} \mathrm{H}_{3}, \mathrm{C}_{2} \mathrm{H}_{4}, \mathrm{C}_{2} \mathrm{H}_{6}$, $\mathrm{CO}, \mathrm{CO}_{2}, \mathrm{CH}_{2}, \mathrm{CH}_{3}, \mathrm{CH}_{4}$, $\mathrm{CH}_{2} \mathrm{O}, \mathrm{CH}_{2} \mathrm{CO}, \mathrm{CH}_{3} \mathrm{O}$, $\mathrm{H}_{2}, \mathrm{H}_{2} \mathrm{O}, \mathrm{H}, \mathrm{HO}_{2}, \mathrm{H}_{2} \mathrm{O}_{2}$, $\mathrm{O}_{2}, \mathrm{O}, \mathrm{OH}$

Table 1. Chemical Kinetics Mechanism of Zambon and Chelliah [13] Incorporated into the Scramjet Engine Analysis.

evaluate $\dot{\omega}_{i}$, the reduced chemical mechanism of Zambon and Chelliah [14] was used. It simulates the kinetics for three possible fuels that are burning in air: ethylene $\left(\mathrm{C}_{2} \mathrm{H}_{4}\right)$, hydrogen $\left(\mathrm{H}_{2}\right)$ and methane $\left(\mathrm{CH}_{4}\right)$. 
It has been validated against experimental data that describes ignition, flame propagation and extinction for a wide range of equivalence ratios, temperatures and pressures. The 18 reactions and 22 species in the kinetics mechanism are listed in Table 1 . The chemical mechanism in Table 1 consists of a FORTRAN code that is imbedded within the MATLAB propulsion code.

The flow equations (1-8) are solved by using the built-in integration capacity of MATLAB. For computer implementation, the equations are combined by using elimination of variables, so that each flow quantity (p, T, $\rho,(\mathrm{MW})^{-}, \mathrm{Y}$, etc.) can be found using an explicit equation, rather than a matrix inversion, which could be time-consuming in some cases. The combustor entrance conditions $\left(\mathrm{U}, \mathrm{T}, \mathrm{p}\right.$, and $\mathrm{Y}_{\mathrm{i}}$ ) are computed from the flight conditions and the bow shock/inlet relations. The mass added profile, is determined from the mixing analysis, and the area profile $\mathrm{A}(\mathrm{x})$ is given. This results in a set of equations in which all quantities can be determined if the equations are solved in order. The differential equations are solved using the MATLAB ODE23TB algorithm. This solver is chosen because it had the best performance (measured in running time) compared to the other available solvers, and because it has the option of preventing the integrands from taking negative values, which is a realistic requirement for this particular problem. It was necessary to choose a solver capable of efficiently handling stiff equations, since there can be large differences in the rates of change of the combustion reaction processes compared to that of state variables.

The 22 species considered in the finite rate reaction mechanism are listed in Table 1; they are typical combustion products. The thermodynamic properties of these 22 species are tabulated in Chemkin. For example, the heat capacity of each of the 22 species is represented as a polynomial function of gas temperature, and the coefficients of each term is stored in the Chemkin data base. Also stored is the enthalpy of formation of each species, which is used to compute the heat released by combustion and the enthalpy recovered during recombination. The chemical reaction rates are determined using the method of Zambon and Chelliah [14] in a separate FORTRAN code, which interfaces with MATLAB as a MEX file. The chemical kinetics subroutine takes the input values of the concentrations of species and outputs a rate of change of each concentration, which is transferred back to the MATLAB code.

\section{Model of the Isolator Section and the Combustor-Isolator Interaction}

\section{V.1 The Pre-Combustion Shock Train in Ram and Scram Modes}

To correctly compute the engine thrust, it is important to determine the stagnation pressure loss across the Pre-Combustion Shock Train (PCST) that will exist in the isolator under certain conditions. The boundary conditions that govern the strength of the PCST are different in the ram and the scram modes. Figure 5 illustrates the flow field that has been observed [15, 28-39] for three modes: ram, early scram and late scram modes. Consider a dual-mode engine accelerated from $\mathrm{M}_{\mathrm{oo}}$ of 3 to 12 , with the fuel flow rate and air mass flow rates held approximately constant. In the ram mode Fig. 5a indicates that the isolator entrance Mach number may be 2.0 and a strong PCST reduces the Mach number to 0.6. Heat is added in both the constant area and the diverging area sections until it thermally chokes the flow. In the ram mode the shock waves create an adverse pressure gradient in the isolator, and cause the boundary layer to be separated. However, there is a favorable pressure gradient in the combustor since in the flow direction the Mach number increases and the static pressure decreases. Therefore it is expected that the boundary layer will reattach at the end of the isolator and remain attached in the combustor during ram mode.

As the vehicle accelerates, the engine inlet Mach number and $\mathrm{T}_{0 \mathrm{oo}}$ increase, and Fig. $5 \mathrm{~b}$ shows that in the Early Scram Mode the Mach number remains supersonic. The strength of the PCST weakens, but there is believed to be an adverse pressure gradient in the combustor, because in the x-direction the Mach number decreases and the static pressure increases. Heiser and Pratt [15] explain that constant pressure combustion is expected to occur during the early scram mode because the separated boundary layer creates a new effective wall shape. As drawn in Fig. 5b, the separated boundary layer is getting thinner in the 
downstream direction so in the x-direction the effective flow area is increasing which tends to cause the static pressure to decrease. This decrease is offset by the increase in static pressure due to heat addition. The thermal choking boundary condition no longer applies in the scram mode. Figure $5 \mathrm{c}$ indicates that further acceleration leads to the disappearance of the PCST, as explained in Ref. 15.

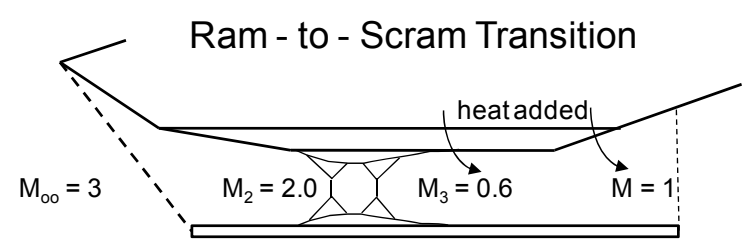

a) Ram mode: strong PCST, no separation in combustor, choked

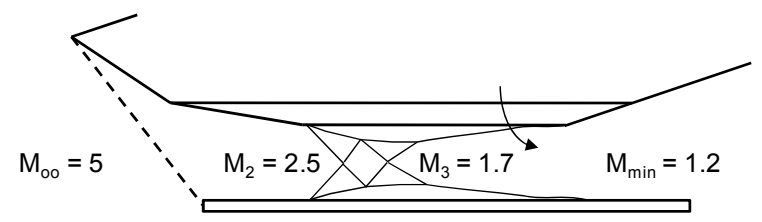

b) Early scram mode: weak PCST, separation in combustor, not choked

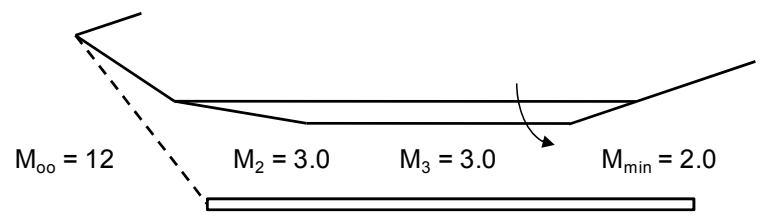

c) Late scram mode: no PCST, not choked

Figure 5. Schematic of Isolator Pre-Combustion Shock Train for Ram, Early Scram and Late Scram Modes

The profiles of Mach number and static pressure through the engine are sketched in Fig. 6 for the Ram-toScram transition that occurs during vehicle acceleration. The three modes (ram, early scram, and late scram) are marked. Note that the ram mode has choked flow at the end of the heat addition process. The early scram mode is characterized by constant pressure heat addition, so the curves in Fig. 6b labeled early scram are horizontal between stations 3 and 4 . The late scram mode is characterized by no PCST, so the curves in Fig. $6 \mathrm{~b}$ labeled late scram are horizontal between stations 2 and 3.

One method to calculate the strength of the PCST in the isolator is to use the empirical curves of Billig et al. [29, 30]. While Billig's empirical method is not used in this work, the results of Billig are presented in Figs. 7 and 8 for comparison. Fig. 7 predicts that if heat is continuously added to an engine that is not accelerating (the engine inlet Mach number is fixed at 2.5), then the PCST will become stronger. Consider the leftmost curve in Fig. 7 marked $A_{4} / A_{3}=1.0$. If no heat is added the flow remains supersonic and $p_{3} / p_{2}$ is 1.0 in this scram mode. As more heat is added the PCST becomes stronger $\left(\mathrm{p}_{3} / \mathrm{p}_{2}\right.$ increases) and there is a transition to ram mode. Figure 8 displays Billig's empirical result for the computed strength of PCST, in terms of vehicle flight Mach number and equivalence ratio. The upper curve in Fig. 8 indicates that for a fixed equivalence ratio of 1.0 the strength of the PCST decreases as the vehicle accelerates from ram to early scram to late scram modes. This trend in Fig. 8 is consistent with the pressures in Fig. $6 \mathrm{~b}$ that occur in the scram mode, while the right portion corresponds to large values of heat addition that occur in the ram mode. 

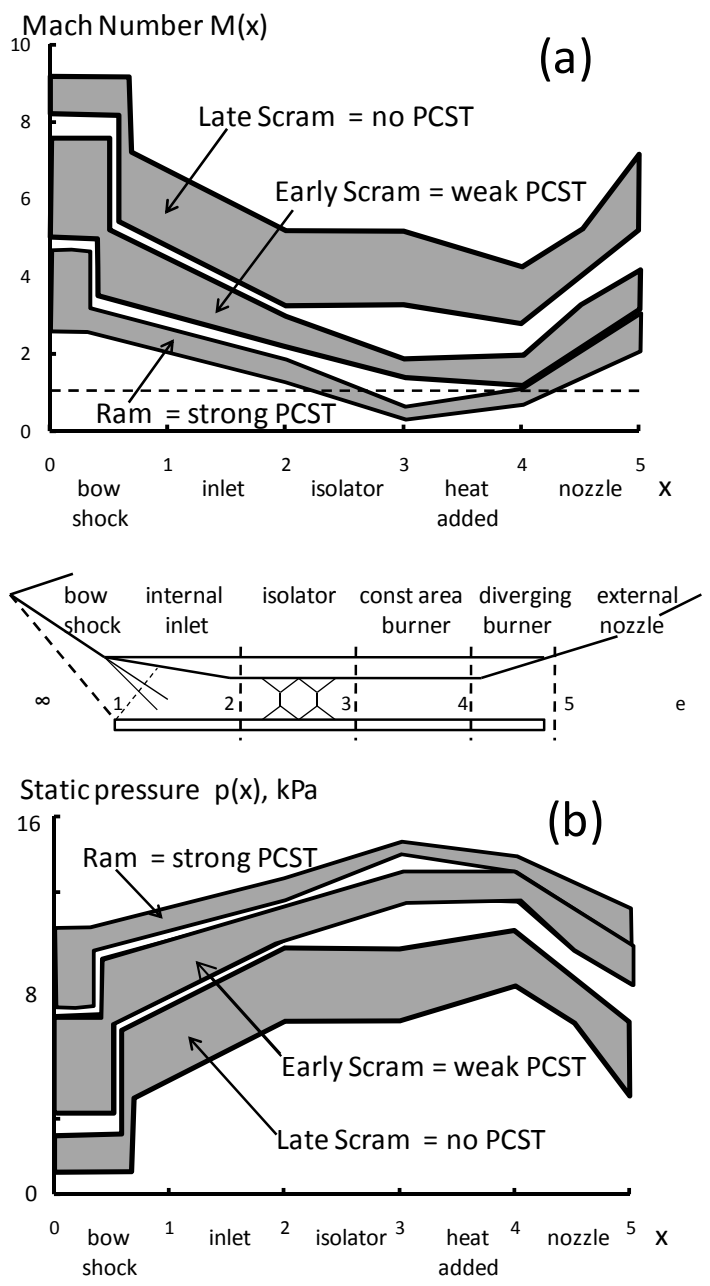

Figure 6. Profiles of Mach Number and Static Pressure for ram, early scram and late scram modes.

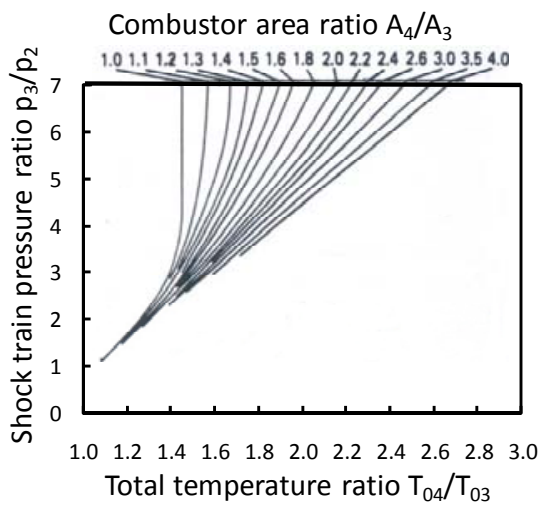

Figure 7. Billig's Empirical Formulas for Strength $\left(\mathrm{p}_{3} / \mathrm{p}_{2}\right)$ of the PCST in the isolator $[29,30]$ for a combustor entrance Mach number of 2.5. The plot is for comparison purposes and was not used in the proposed propulsion model. The left portion of each curve corresponds to small values of heat addition 


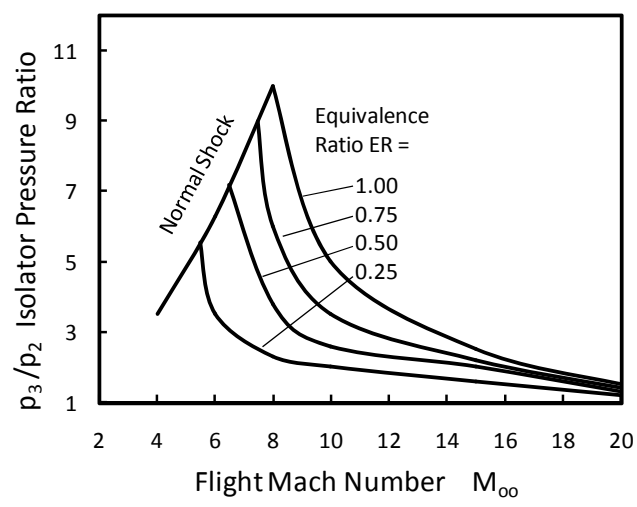

Figure 8. Billig's Empirical Formulas for Strength of PCST, in terms of vehicle flight Mach number and Equivalence Ratio [29]. The plot is for comparison and was not used in the proposed propulsion model.

\section{V2. Method to Compute Strength of Pre-Combustion Shock Train}

Three methods have been used in the past to compute the strength of the PCST: the empirical method of Billig et al. [29-33], the constant impulse function method of Heiser and Pratt [15, Eq. 6-88b], and the full CFD solution, such as that of Baurle and Eklund [34]. The empirical method of Billig leads to curves such as those in Figs. 7 and 8 but it suffers from the fact that several of his equations are empirical curvefits. It cannot be determined over what range of conditions these curvefits are valid. Billig assumes that a "pressure-area" correlation is valid, but this critical assumption has not been adequately validated by experiments or rigorous theory. He also assumes that the correct solution corresponds to what he denotes his "entropy limit"; his analysis leads to several possible solutions and he chooses the one that predicts the lowest downstream pressure to be the entropy limit. The full CFD solution of Baurle and Eklund [34] is attractive because it accounts for 3-D boundary layer separation and complex shock patterns, but to date only a small number of cases have been computed with acceptable accuracy. What is needed is a complete set of curves describing the effects of varying all the governing parameters - such as heat release, area change, inlet Mach number, inlet stagnation temperature and pressure.

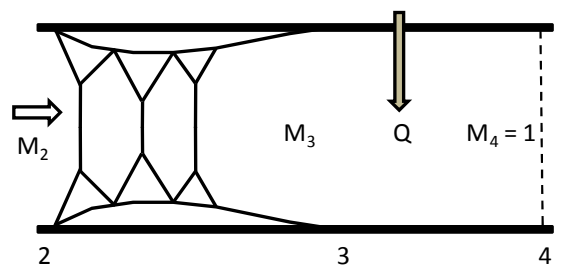

Figure 9. Simple Case of Pre-Combustion Shock Train With No Separation in the Combustor and With Thermal Choking

In the present model, the strength of the PCST is computed using the constant impulse function method of Heiser and Pratt [15]. To understand why a PCST exists, first consider the simplified case shown in Fig. 9. A known amount of heat is added between stations 3 and 4 that causes thermal choking at station 4. Conditions at station 2 are known, based on the known bow shock and inlet shock strengths. For this simplified example it is assumed that there is no heat loss or frictional losses, $\mathrm{c}_{\mathrm{p}}$ is constant, and there is no gas dissociation. These assumptions are relaxed later. The Mach number at station 3 is computed directly from the Rayleigh line tables; $\mathrm{T}_{03}$ equals $\mathrm{T}_{02}$, and $\mathrm{T}_{04}$ is known from the given amount of heat addition. $\mathrm{T}_{04}=\mathrm{T}_{04}{ }^{*}=\mathrm{T}_{03}{ }^{*}$, so the known ratio of $\mathrm{T}_{03} / \mathrm{T}_{03} *$ yields the Mach number $\mathrm{M}_{3}$. The next step is to compute the value of $\mathrm{p}_{03}$ from the conservation of mass [9] betweens stations 2 and 3 : 


$$
p_{03}=p_{02} \quad \frac{\left(A_{2}^{*} / A_{2}\right)}{\left(A_{3}^{*} / A_{3}\right)} \frac{1}{\left(A_{3} / A_{2}\right)}
$$

The ratios $\left(A_{2} * / A_{2}\right)$ and $\left(A_{3} * / A_{3}\right)$ are functions of the known values of $M_{2}$ and $M_{3}$. For this simple example, assume that the boundary layer reattaches at location 3 so that the ratio $A_{3} / A_{2}$ is unity. The final step is to compute $\mathrm{p}_{3}$; now that $\mathrm{p}_{03}$ has been calculated using Eq. 27, the values of $\mathrm{p}_{03}$ and $\mathrm{M}_{3}$ are combined to compute $\mathrm{p}_{3}$ and thus the PCST strength $\left(\mathrm{p}_{3} / \mathrm{p}_{2}\right)$. This simple example shows that as more heat is added, the Mach number $\mathrm{M}_{3}$ is driven to a smaller value, and this requires that the shock waves in the PCST to become stronger. Thus increasing the heat addition causes the PCST pressure ratio $\left(\mathrm{p}_{3} / \mathrm{p}_{2}\right)$ to increase, which is in agreement with the empirical curves of Billig shown in Fig. 7.

The constant impulse function method of Heiser and Pratt [15] is more realistic that the above method, since it replaces the unrealistic assumption that $A_{3} / A_{2}$ is unity with the more realistic assumption that the impulse function ( $\mathrm{I}=\mathrm{pA}+\dot{m} \mathrm{U})$ is constant between stations 2 and 3. Refs. 9 and 15 describe the momentum equation, which can be written as:

$$
\begin{aligned}
& \mathrm{I}_{2}-\mathrm{I}_{3}=\text { viscous force on walls }=0 \\
& \mathrm{I}_{2}=\mathrm{p}_{2} \mathrm{~A}_{2}+\dot{m} \mathrm{U}_{2} \\
& \mathrm{I}_{3}=\mathrm{p}_{3}\left(\mathrm{~A}_{2}-\mathrm{A}_{3 \mathrm{c}}\right)+\mathrm{p}_{3} \mathrm{~A}_{3 \mathrm{c}}+\dot{m} \mathrm{U}_{3}
\end{aligned}
$$

The last equation assumes that the flow at station 3 consists of a central core region in which the gas velocity is $\mathrm{U}_{3}$, and the surrounding annular region is a separated flow region in which the gas velocity is zero. $\mathrm{I}_{3}$ is the sum of the impulse function for the two regions. If Eqs $28-30$ are combined and is $\dot{m}$ is replaced with $\rho_{2} \mathrm{U}_{2} \mathrm{~A}_{2}$, Ref. 15 (Eq. 6-88b) shows that the strength of the PCST is:

$$
\frac{p_{3}}{p_{2}}=\left(1+\gamma M_{2}^{2}\right)-g M_{2} M_{3} \sqrt{\frac{1+\frac{\gamma-1}{2} M_{2}^{2}}{1+\frac{\gamma-1}{2} M_{3}^{2}}}
$$

To determine $\mathrm{M}_{3}$ in Eq. 31, the Rayleigh relation [9] is used, which is, for the case of $\mathrm{M}_{4}$ equal to unity:

$$
\frac{2(\gamma+1) M_{3}^{2}\left(1+\frac{\gamma-1}{2} M_{3}^{2}\right)}{\left(1+\gamma M_{3}^{2}\right)^{2}}=\left(\frac{T_{04}}{T_{03}}\right)^{-1}
$$

The Rayleigh line relation (Eq. 32) predicts that adding more heat in the ram mode $\left(\mathrm{M}_{4}=1\right)$ drives the Mach number $M_{3}$ to a smaller value. This in turn causes the PCST pressure ratio $\left(\mathrm{p}_{3} / \mathrm{p}_{2}\right)$ to increase, according to Eq. 31. Some results of the computation are reported in the following section. Future efforts are planned to use CFD and experimental data to assess the assumption of constant impulse function and the two annular stream concept used to derive Eq. 30 for the separated flow in the Ram Mode.

Next we consider the Early Scram mode operation that was shown in Fig. 5b. Transition from Ram to Early Scram mode is achieved either by increasing the flight Mach number or by reducing the amount of fuel added. In the Early Scam mode, the engine is not thermally choked and there would be an adverse pressure gradient in the heat addition region (region 3-4) if the boundary layer remained attached, since heat addition to a supersonic flow decreases the Mach number and increases pressure in the xdirection. Experiments show that the boundary layer becomes separated and the area of the core flow varies such that the pressure remains constant in the x-direction. It is argued by Heiser and Pratt [15] that the Early Scram mode is characterized by the following boundary condition:

$$
\mathrm{p}_{3}=\mathrm{p}_{4}=\mathrm{p}_{4, \mathrm{NP}}
$$


where $\left(\mathrm{p}_{4}\right)_{\mathrm{NP}}$ is the pressure that would be computed at location 4 if there was no PCST present in the isolator. The value of $\mathrm{p}_{4, \mathrm{NP}}$ is easily computed by marching from station 2 to 4 . Conditions at 3 are identical to 2 for this hypothetical case of no PCST. The Rayleigh line is used to march from 3 to 4 .

It also is necessary to define when the early scram mode (the constant pressure heat addition) occurs. Heiser and Pratt [15] state that experiments show that the boundary layer in the heat addition region is not separated during high Mach number (Late Scram) flight conditions, but as more heat is added (or the flight Mach number is reduced) the supersonic boundary layer becomes separated and causes the pressure to be constant in the heat addition region when:

$$
\mathrm{M}_{4, \mathrm{NP}} \leq 0.76 \mathrm{M}_{3, \mathrm{NP}}
$$
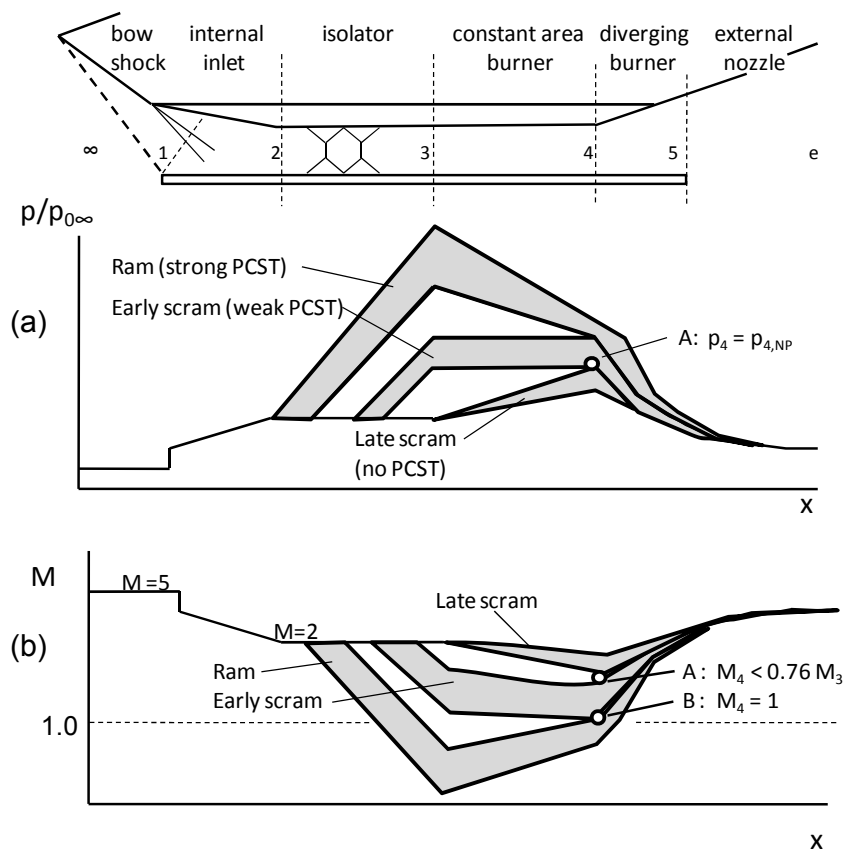

Figure 10. Schematic of (a) static pressures and (b) Mach numbers for a dual-mode scramjet that is operated at a constant flight Mach number and at a constant altitude, but the fuel flow rate is varied. Boundaries of the early scram mode are identified by points A and B.

Thus when both sides of Eq. 34 are equal, this marks the boundary between the Late Scram and the Early Scram modes. $\mathrm{M}_{4, \mathrm{NP}}$ and $\mathrm{M}_{3, \mathrm{NP}}$ are easily determined by the same method that was used to compute $\mathrm{p}_{4, \mathrm{NP}}$. Eq. 34 is not applicable to the ram mode, which always has a favorable pressure gradient where heat is added. To understand Eqs. 33 and 34, consider the profiles drawn in Fig. 10. For simplicity we consider the case of scramjet operating at a constant Mach number of 5 at a constant altitude. Initially the scramjet is operated in the Late Scram mode (corresponding to a small amount of fuel) and more fuel is added until a Scram-to-Ram transition occurs. This case is the easiest to explain because all quantities remain fixed at station 2, which is the entrance to the isolator, although this may not be a realistic way to operate a hypersonic vehicle.

V.2.a) Late Scram Mode (no PCST) corresponds to the lower grey region in Fig. 10a and the upper grey region in Fig. 10b. Note that in the isolator (2-3) there is constant pressure and constant Mach number since there is no PCST. The flow is supersonic and is not choked. The quantity $\mathrm{p}_{4, \mathrm{NP}}$ is defined as the pressure at station 4 when there is no PCST in the isolator. To compute $\mathrm{p}_{4, \mathrm{NP}}$ the following procedure is used. All conditions at station 3 are identical to the known conditions at station 2. For a selected amount of heat addition the value of $\left(\mathrm{T}_{04}-\mathrm{T}_{03}\right)$ is given, so $\mathrm{T}_{04}$ is known. The Rayleigh line tables are used to 
compute $\mathrm{M}_{4}, \mathrm{p}_{04}$ and $\mathrm{p}_{4}$. The quantity $\mathrm{p}_{4, \mathrm{NP}}$ is the value of $\mathrm{p}_{4}$ that is calculated in the manner described previously.

V.2.b) Early Scram Mode (weak PCST) is the central grey regions in Figs. 10a and 10b. The figure shows that for a very small amount of heat added, the Mach number at station 4 lies above the point marked " $\mathrm{A}$ ", and as heat is added $\mathrm{M}_{4}$ decreases until it reaches point $\mathrm{A}$. As the heat addition increases, $\mathrm{M}_{3}$ remains constant. At point A, the boundary layer in between 3 and 4 separates and the heat addition process occurs at constant pressure. Figure 10a shows that a PCST now must form; note that the pressure curve that passes through point $\mathrm{A}$ is a horizontal line between stations 3 and 4 , therefore $\mathrm{p}_{3}$ becomes larger than $\mathrm{p}_{2}$ when the constant-pressure separated boundary layer occurs. Thus a pressure rise must occur between stations 2 and 3. Heiser and Pratt [15] argue that this transition to a separated boundary layer occurs at $\mathrm{M}_{4, \mathrm{NP}}=0.76 \mathrm{M}_{3, \mathrm{NP}}$, so this criterion is adopted in the present model. Note that in Fig. 10a the point $\mathrm{A}$ is marked with the label $\mathrm{p}_{4}=\mathrm{p}_{4, \mathrm{NP}}$. Point $\mathrm{A}$ is on the boundary between the Late Scram and the Early Scram modes, so a PCST has not yet formed. Therefore the boundary condition:

$$
\mathrm{p}_{4}=\mathrm{p}_{4, \mathrm{NP}}
$$

must be valid at the boundary of the early scram condition. When heat is added both of the quantities $\mathrm{p}_{4}$ and $\mathrm{p}_{4, \mathrm{NP}}$ must increase in a similar manner within the early scram mode. Therefore the strength of the PCST in early scam mode is computed as follows. First the quantity $\mathrm{p}_{4, \mathrm{NP}}$ is computed from the known amount of heat added using the method described in part (a) above. Since $\mathrm{p}_{4, \mathrm{NP}}$ is the hypothetical pressure at 4 that would occur if there was no PCST, in the computation of $\mathrm{p}_{4, \mathrm{NP}}$ it is assumed that there is no PCST. Then Eq. 35 is invoked, and since pressure is constant in the heat release region, $\mathrm{p}_{3}=\mathrm{p}_{4}=\mathrm{p}_{4, \mathrm{NP}}$. The strength of the PCST is this value of $\mathrm{p}_{3}$ divided by the known value of $\mathrm{p}_{2} . \mathrm{M}_{3}$ can then be determined by combining the conservation of mass (Eq. 27). As additional heat is added in the early scram mode, Fig. 10 shows that the PCST becomes stronger and longer - it starts at a location that moves upstream. The engine remains in the early scram mode until $\mathrm{M}_{4}$ decreases to unity, which is identified by point $\mathrm{B}$ in Fig. 10b.

V.2.c) Ram Mode (Strong PCST) occurs if additional heat is added after $M_{4}$ has decreased to unity (point B in Fig. 10b). The method to compute the strength of the PCST in the ram mode using Eqs. 31 and 32 was described at the beginning of this section. The flow must be thermally choked at all times during ram mode operation since there is no physical throat between the subsonic combustor and the supersonic nozzle. In the ram mode, Heiser and Pratt [15] points out that it is necessary to add only a portion of the fuel in the constant area section 3-4 and the rest should be added into the diverging area section 4-5 4 to avoid unstart.

Figure 11 is a summary of the Ram-To-Scram solution algorithm for the simple case of no gas dissociation with a constant area isolator and combustor. The algorithm in Fig. 11 is presented for the simplest case in order to explain the logic for the case when only algebraic equations are required. In order to include gas dissociation and variable areas, the full model must be used, so the logic of Fig. 11 is applied and the differential equations (Eqs. 1-8) replace the Rayleigh line and constant pressure formulas. 
Select $\mathrm{M}_{00}$, altitude, dynamic pressure, ER

Compute all properties at $2=$ entrance to isolator, using oblique shock tables

First iteration: assume no PCST

All properties at 3 (exit of isolator)= properties at 2 (entrance to isolator)

Compute $\left(\Delta \mathrm{T}_{0}\right)_{\text {choke }}=\Delta \mathrm{T}_{0}$ required to choke location 4 (exit of combustor)

Compute $\Delta \mathrm{T}_{0}=$ actual stagnation temperature rise caused by the operating ER

If $\Delta \mathrm{T}_{0}>\left(\Delta \mathrm{T}_{0}\right)_{\text {choke, }}$ Engine is in Ram Mode, set $\mathrm{M}_{4}=1.0$, compute strength of PCST using Eqs. 31 and 32

If $\Delta \mathrm{T}_{0}<\left(\Delta \mathrm{T}_{0}\right)_{\text {choke }}$, Engine is in Scram Mode, either Early Scram or Late Scram Compute $\mathrm{M}_{4, \mathrm{NP}}=\mathrm{M}_{4}$ with no PCST, using Rayleigh line marching technique Compute $\mathrm{p}_{4, \mathrm{NP}}=\mathrm{p}_{4}$ with no PCST, using Rayleigh line marching technique Compute $\mathrm{M}_{3, \mathrm{NP}}=\mathrm{M}_{3}$ with no PCST

If $\mathrm{M}_{4, \mathrm{NP}}>0.76 \mathrm{M}_{3, \mathrm{NP}} \quad$ Engine is in Late Scram Mode, there is no PCST, so $\mathrm{p}_{3}=\mathrm{p}_{2}, \mathrm{M}_{4}=\mathrm{M}_{4, \mathrm{NP}}, \mathrm{M}_{3}=\mathrm{M}_{3, \mathrm{NP}}$

If $\mathrm{M}_{4, \mathrm{NP}}<0.76 \mathrm{M}_{3, \mathrm{NP}}$

Engine is in Early Scram Mode, there is a weak PCST and constantpressure combustion, $\mathrm{p}_{3}=\mathrm{p}_{4}=\mathrm{p}_{4, \mathrm{NP}}$, so $\mathrm{p}_{3} / \mathrm{p}_{2}$ across PCST now known Compute $\mathrm{p}_{03}, \mathrm{M}_{3}$ using cons. of mass across isolator (Eq. 27) Compute $\mathrm{M}_{4}$ using constant pressure heat addn formulas (Heiser \& Pratt)

Figure 11. Logic of the Ram-to-Scram Solution Algorithm for the Simple Case of No Dissociation and Constant Area Inlet and Combustor (Heiser and Pratt[15]). The proposed model uses similar logic but employs differential equations instead of the Rayleigh line or constant pressure formulas to account for gas dissociation, area change, heat loss to walls and wall friction.

\section{Dissociation Losses Across Shock Waves in the Inlet and Isolator}

The static temperature downstream of the bow shock wave usually is too low to cause appreciable gas dissociation, since the typical gas temperature ahead of the bow shock is $220 \mathrm{~K}$ and the flow turning angle is small (typically $6^{\circ}$ ). However, as the engine airflow is decelerated by strong shock waves inside the inlet and isolator, the static temperature rises, causing gas dissociation and an effective loss of stagnation temperature, some of which can be recovered during recombination in the nozzle. A subroutine in the engine code accounts for dissociation caused by shock waves using the method outlined in Anderson [16]. The method is exact; it accounts for real gas changes to the heat capacity. It assumes that the chemical processes associated with $\mathrm{N}_{2}$ and $\mathrm{O}_{2}$ dissociation are so fast that chemical equilibrium is achieved rapidly. The subroutine handles both oblique and normal shocks; only the latter will be described here for simplicity. Anderson [16, p. 507] writes the following conservation equations across a normal shock:

$$
\begin{aligned}
& \rho_{2} U_{2}=\rho_{1} U_{1} \\
& p_{2}+\rho_{2} U_{2}^{2}=p_{1}+\rho_{1} U_{1}^{2}
\end{aligned}
$$




$$
\begin{aligned}
& h_{2}+U_{2}^{2} / 2=h_{1}+U_{1}^{2} / 2 \\
& p_{2}=\rho_{2} R_{u} T_{2} / M W_{2}
\end{aligned}
$$

Real gas effects are considered by expressing the enthalpy/mass in terms of the contributions from each species:

$$
h_{2}=\sum_{i} Y_{i} h_{i}
$$

The enthalpy/mass for each species is composed of its heat of formation and its sensible enthalpy:

$$
h_{i}=h_{f, i}^{o}+\int_{298 K}^{T} c_{p, i} d T
$$

Heat capacity $c_{p, i}$ is expressed as a polynomial function of the gas temperature using the valued in the CHEMKIN code, and the mass fraction is related to mole fraction by:

$$
Y_{i}=\sum_{i} X_{i} M W_{i}
$$

The molecular weight of the mixture downstream of the shock is:

$$
M W_{2}=\sum_{i} X_{i} M W_{i}
$$

The mole fractions $\left(\mathrm{X}_{\mathrm{i}}\right)$ of $\mathrm{O}_{2}, \mathrm{O}, \mathrm{N}_{2}, \mathrm{~N}$ and $\mathrm{NO}$ are related to each other by the Law of Mass Action for a system in chemical equilibrium. For example, for the reaction $\mathrm{O} \leftarrow \rightarrow 1 / 2 \mathrm{O}_{2}$ the equilibrium constant $\mathrm{K}_{\mathrm{p}}$ relates $\mathrm{X}_{\mathrm{O} 2}$ to $\mathrm{X}_{\mathrm{O}}$ in the following way:

$$
K_{p, 1}=\frac{X_{O_{2}}^{1 / 2}}{X_{O}}\left(\frac{p_{2}}{p_{\text {ref }}}\right)^{-1 / 2}
$$

Additional equilibrium relations are written to relate the mole fractions of $\mathrm{N}, \mathrm{N}_{2}$ and NO. Equations 28 to 36 are solved using the algorithm suggested by Anderson [16, p. 507].

\section{Results}

Figure 12 illustrates the loss in stagnation temperature associated with gas dissociation across a normal shock wave. When the compression caused by all of the inlet shock waves are added, the maximum possible compression is that of a single normal shock wave. The losses plotted in Fig. 12 represent a worst-case scenario. The altitude was set to $32 \mathrm{~km}$. Fig. 12 indicates that at Mach 15 the gas dissociation could cause a loss of $26 \%$ of the stagnation temperature, which is a significant loss of the total enthalpy available to provide thrust, if the sum of the inlet shock compression is close to the normal shock

limit. Fortunately a large fraction of this dissociation loss can be recovered during gas recombination in the exhaust nozzle. At flight Mach numbers below 8, less than 5\% of the stagnation temperature is lost by dissociation. However, additional dissociation occurs across the inlet shock waves and in the combustor.

The strength of the pre-combustion shock train was computed using the method described by Eqs. 31 and 32 for several cases. When the engine operates in the ram mode some results are shown in Fig. 13. The combustor entrance Mach number is 2.0 and the exit of the combustor is choked $\left(\mathrm{M}_{4}=1\right)$. As the heat addition parameter $\left(\mathrm{T}_{04} / \mathrm{T}_{03}\right)$ is increased, the strength of the PCST is seen to increase; this trend is similar to that of Billig's empirical curves in Fig. 7. The distance to mix the fuel to the rich flammability limit was computed using Eq. 23 and some results are shown in Fig. 14. For this example the flight Mach number was chosen to be 6.0 and engine equivalence ratio is 0.4 . The diameter of each fuel jet injector is $1 \mathrm{~cm}$. The nominal air velocity $\mathrm{U}_{\mathrm{A}}$ at the injector is $1428 \mathrm{~m} / \mathrm{s}$ and the resulting mixing length is $0.61 \mathrm{~m}$. Figure 
14 indicates that if $\mathrm{U}_{\mathrm{A}}$ is increased, the mixing length increases. Two competing effects occur; more air is forced into the jet which tends to shorten the mixing distance, but the increased convection velocity forces the mixing region to extend farther downstream.

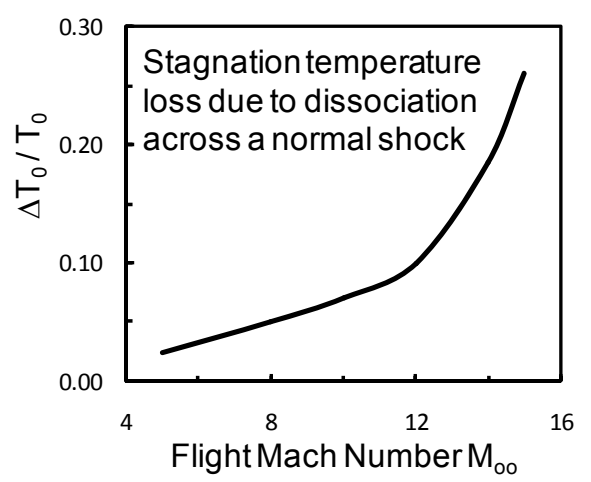

Fig. 12. Stagnation Temperature Loss Across the Bow Shock Due to Gas Dissociation, Computed From Eqs. 36 - 44.

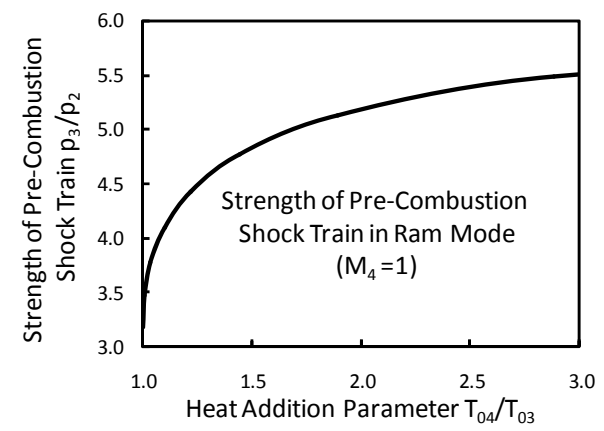

Figure 13. Strength of the Pre-Combustion Shock Train Computed Using Eqs. 31 and 32, which is the Constant Impulse Function Method of Heiser and Pratt [15, Eq. 6-88b]. Ramjet mode, thermally choked $\left(\mathrm{M}_{4}=1\right)$, combustor entrance Mach number $=2.0$.

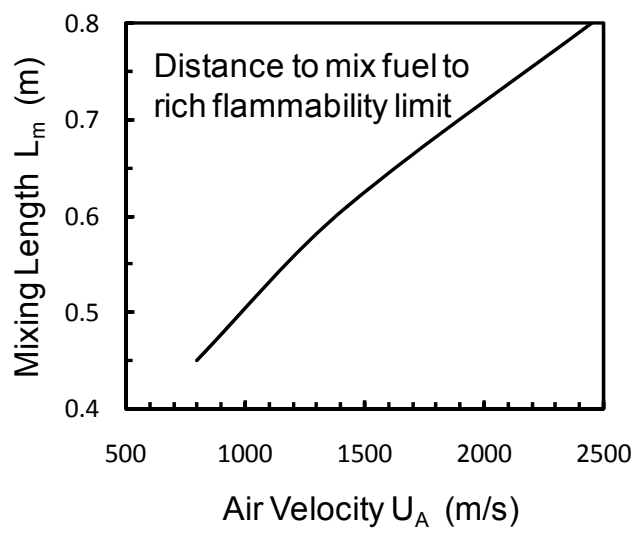

Figure 14. Computed distance in meters to mix hydrogen fuel with air to the rich flammability limit, where the autoignition kinetics would begin to react the fuel. Eq. 26 was used, with injector diameter (d) of $1 \mathrm{~cm}$, fuel injection velocity $U_{F}=1100 \mathrm{~m} / \mathrm{s}$ (sonic), air density $=0.73 \mathrm{~kg} / \mathrm{m}^{3}$. 

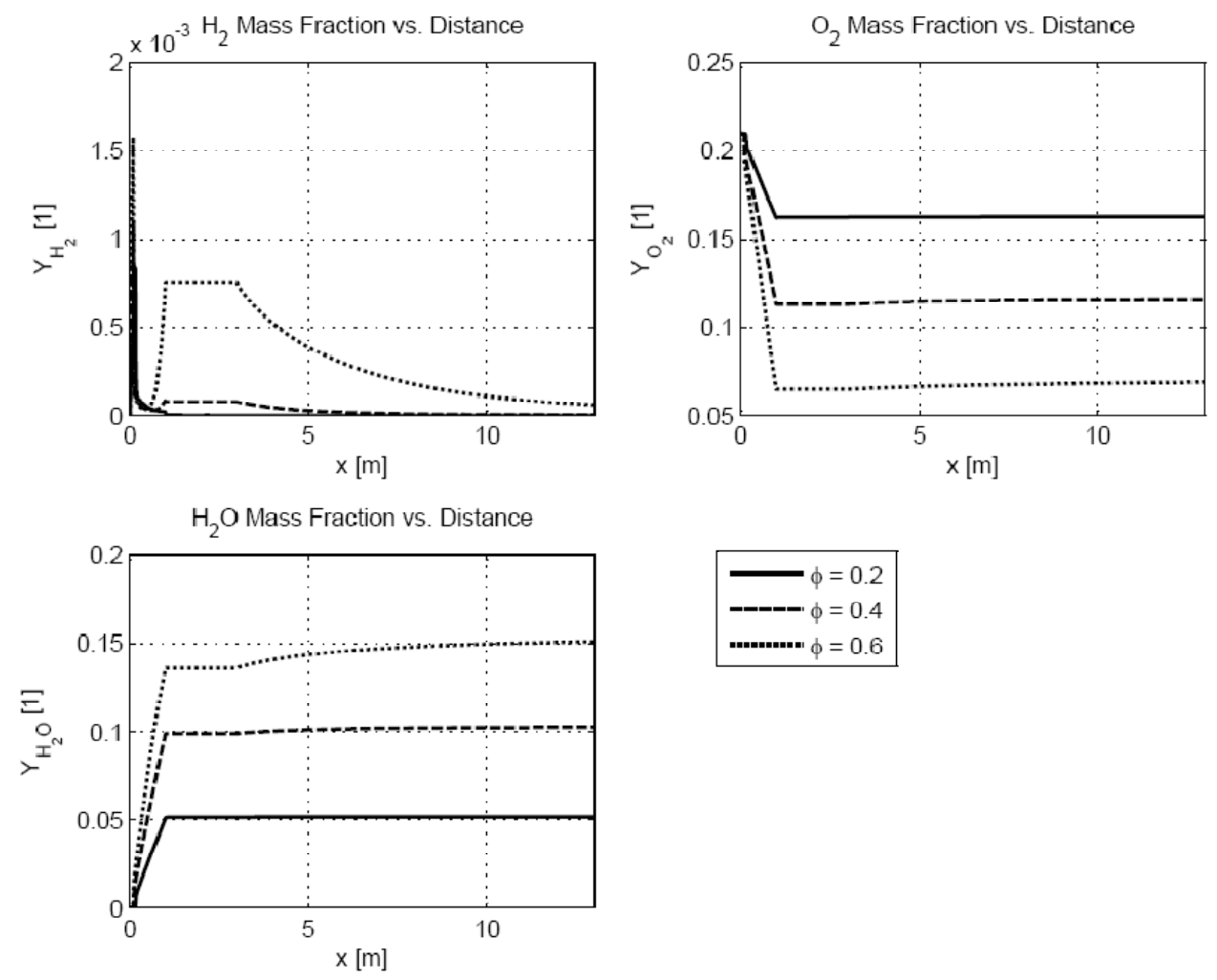

Figure 15. Some Results of the Model: Eqs. 1-8 Were Solved to Compute the Mass Fraction of $\mathrm{H}_{2} \mathrm{O}, \mathrm{H}_{2}$ and $\mathrm{O}_{2}$ in the Combustor and Nozzle Sections for the Late Scram Mode (no PCST). Constant area combustor is $3 \mathrm{~m}$ long; the nozzle is $10 \mathrm{~m}$ long. Nozzle exit area is 3.1 times the combustor area. Combustor inlet Mach number $=3.0, \mathrm{~T}_{03}=3200 \mathrm{~K}$. Hydrogen fuel injected through $1 \mathrm{~cm}$ diameter ports at three equivalence ratios $(\phi)$ of $0.2,0.4,0.6$. Note that recombination continues into the nozzle $(3 \mathrm{~m}<\mathrm{x}<13 \mathrm{~m})$. Chemical kinetic mechanism is that of Zambon and Chelliah [14].

Figure 15 shows some results of the model. The geometry is that of a constant area combustor that is $3 \mathrm{~m}$ long, followed by a nozzle that is $10 \mathrm{~m}$ long. The nozzle exit area is 3.1 times the combustor area. The combustor inlet Mach number is 3.0 and $\mathrm{T}_{03}$ is $3200 \mathrm{~K}$. Three different equivalence ratios were chosen to be $0.2,0.4,0.6$. Fig. 15 displays the computed mass fractions of $\mathrm{H}_{2} \mathrm{O}, \mathrm{H}_{2}$ and $\mathrm{O}_{2}$. The $\mathrm{H}_{2} \mathrm{O}$ mass fraction rises rapidly at $\mathrm{x}=0$ where the hydrogen is injected. The rate of rise of $\mathrm{H}_{2} \mathrm{O}$ depends on both the fuel-air mixing rate and the chemical kinetics. There is a flat region to the $\mathrm{H}_{2} \mathrm{O}$ curves because it is believed that the fuel has been fully consumed. Later in the nozzle $(3 \mathrm{~m}<\mathrm{x}<13 \mathrm{~m})$ it is noted that $\mathrm{H}_{2} \mathrm{O}$ rises again, due to the recombination of $\mathrm{OH}$ and $\mathrm{H}$ to $\mathrm{H}_{2} \mathrm{O}$. For all three equivalence ratios the mixing distances $\left(\mathrm{L}_{\mathrm{m}}\right)$ were set to be equal, by adjusting the stagnation pressure of the fuel.

In Fig. 16 the profiles of Mach number indicate that the flow remains supersonic everywhere. For the largest equivalence ratio considered (0.4) the heat additions drives the Mach number down to 1.4. the static temperature rises to as large as $3000 \mathrm{~K}$, but this is considerably less than (and more realistic than) what would be computed if real gas effects and dissociation were neglected. Note that the stagnation temperature profile in Fig. 16 indicates that significant rise in $T_{0}$ occurs in the nozzle. Since there was no $T_{0}$ rise in the region from 2 to $3 \mathrm{~m}$, it is concluded that all of the fuel was consumed in the combustor and the $\mathrm{T}_{0}$ rise in the nozzle is entirely due to recombination reactions. Detailed plots such as Figs. 15 and 16 are 
useful to engine designers for a number of reasons. If the static pressure in the combustor becomes too low, the rate of chemical kinetics will drop rapidly and the reaction can extinguish. If a slower burning fuel such as ethylene or methane is used, the chemical reaction rate also may be insufficient. The above results correspond to the late scram mode. Analysis of the ram mode and the early scram mode will be reported in a future paper.
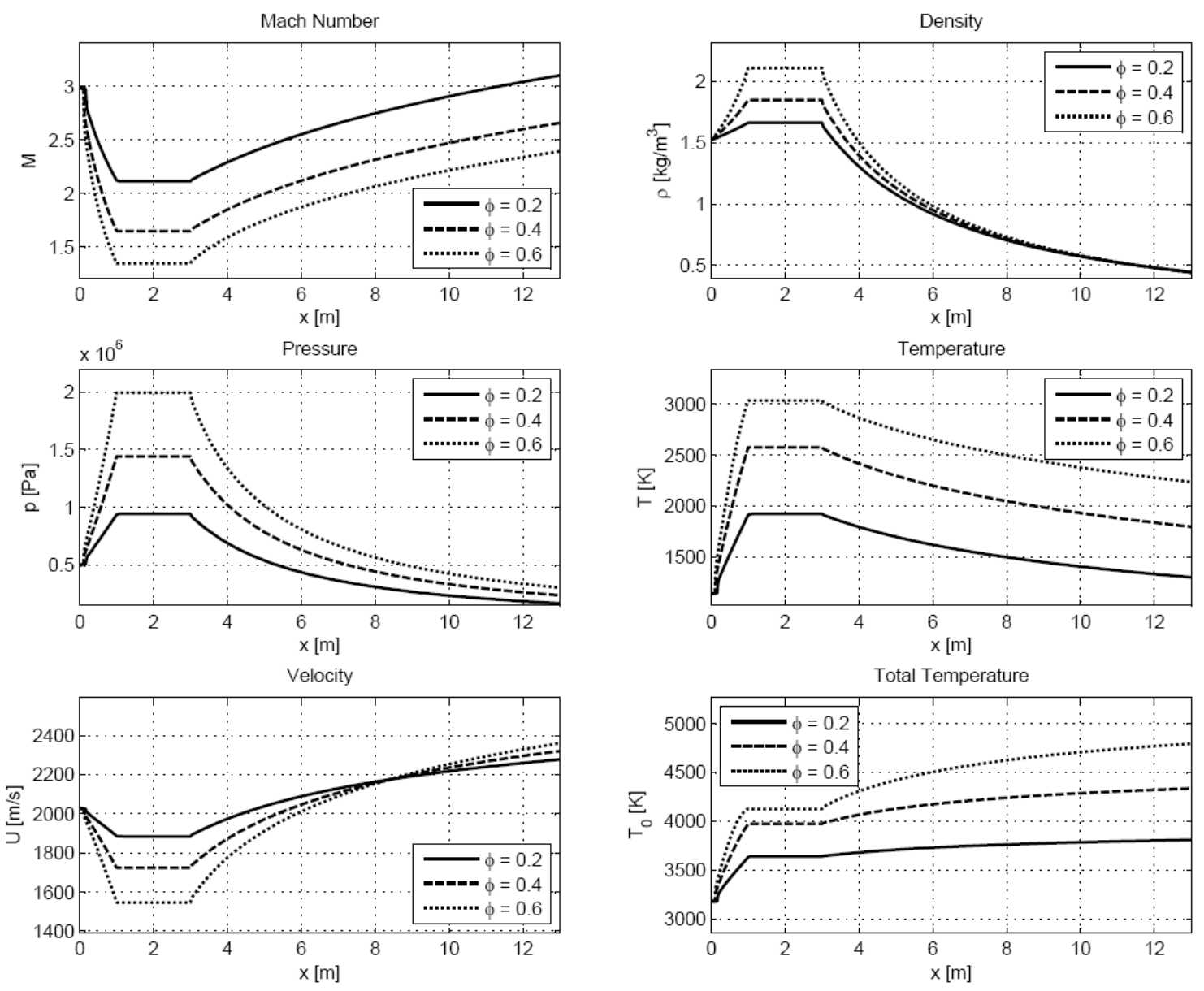

Figure 16. Some Results of the Model: Computed Mach Number, Pressure, Velocity, Density, Static Temperature and Stagnation Temperature in the Combustor and Nozzle Sections. Constant area combustor is $3 \mathrm{~m}$ long; the nozzle is $10 \mathrm{~m}$ long. Nozzle exit area is 3.1 times the combustor area. Combustor inlet Mach number $=3.0, \mathrm{~T}_{03}=3200 \mathrm{~K}$. Hydrogen fuel injected through $1 \mathrm{~cm}$ diameter ports at three equivalence ratios of $0.2,0.4,0.6$.

\section{Conclusions}

It was demonstrated that a new scamjet engine model could be developed that is of higher fidelity than previous models that have been used to support hypersonic vehicle flight dynamics and control system analysis. The methodology and the governing equations are described. Methods to handle the ram-scarm transition, the pre-combustion shock train, the fuel-air mixing, and the dissociation/recombination chemical reactions are discussed. While only a few preliminary results are presented, these results show that significant increases in the stagnation temperature occur in the nozzle due to the recombination reactions. The mixing distance (required to mix fuel and air to the rich flammability limit) increases with the air 
velocity and is in the realistic range of 0.5 to 0.8 meters for the design conditions selected. The computed pressure ratio across the pre-combustion shock train varies from 3.0 to 5.5 for the design conditions chosen. For an engine inlet Mach number of 3.0, the pressure rise due to combustion increases proportionally to the engine equivalence ratio. The largest pressure ratio across the combustor was computed to be 4.0 for an engine equivalence ratio of 0.6. The work also identifies several aspects of the model that require further research. The mixing properties of a fuel jet in a subsonic cross flow are well documented, but the effects of a supersonic flow on the scalar mixing field require more careful analysis. The constant impulse function method to compute the strength of the pre-combustion shock train may require improvement. As CFD results become available, these results will make it possible to assess each of the components of the scramjet engine model in more detail.

\section{Acknowledgements}

Funds for the Michigan-AFRL Collaborative Center in Control Science (MACCCS) were made available from the Air Force Research Laboratory Air Vehicles Directorate grant number FA 8650-07-2-3744.

\section{References}

1. Bolender, M. A. and Doman, D. B., "Nonlinear Longitudinal Dynamical Model of an Air-Breathing Hypersonic Vehicle," Journal of Spacecraft and Rockets, Vol. 44, No. 2, 2007, pp. 374-387.

2. Oppenheimer, M.W. and Doman, D. B., "A Hypersonic Vehicle Model Developed with Piston Theory" AIAA 2006-6637, 2006.

3. Oppenheimer, M. W., Doman, D. B., Bolender, M. A., and Skujins, T., "A Flexible Hypersonic Vehicle Model Developed with Piston Theory," AIAA Paper 2007-6396, 2007.

4. Oppenheimer, M. W. and Doman, D. B., "Viscous Effects for A Hypersonic Vehicle Model," In preparation for submittal to the 2008 AIAA Atmospheric Flight Mechanics Conference.

5. Williams, T., Bolender, M. A., Doman, D. B., and Morataya, O., "An Aerothermal Flexible Mode Analysis of a Hypersonic Vehicle," AIAA Paper 2006-6647, 2006.

6. Bolender, M.A. and Doman, D.B., "Nonlinear Longitudinal Dynamical Model of an Air-Breathing Hypersonic Vehicle", J. Spacecraft and Rockets Vol. 44, No. 2, 2007, pp. 374-387.

7. Chavez, F.R. and Schmidt, D.K., "Analytical Aeropropulsive/Aeroelastic Hypersonic Vehicle Model", J. Guidance, Control, Dynamics Vol.17,No. 6, 1994, pp.1308-1317.

8. Tarpley, C. and Lewis, M.J., "Stability Derivatives for a Hypersonic Caret Wing Waverider", J. Aircraft Vol. 32,No. 4, 1995, pp.795-801.

9. Shapiro, A.H., Dynamics and Thermodynamics of Compressible Fluid Flow, Ronald Press NY, 1953.

10. O’Brien, T.F., Starkey, R.P., Lewis, M.J., "Quasi-One-Dimensional High-Speed Engine Model with Finite-Rate Chemistry". J. Propulsion and Power Vol. 17, No. 6, 2001, pp. 1366-1374.

11. Starkey, R.P., "Off-Design Performance Characterization of a Variable Geometry Scramjet", AIAA Paper 2005-3711, 2005.

12. Birzer, C., Doolan, C.J., "Quasi-One-Dimensional Modeling of Hydrogen Fuelled Scramjet Combustors". AIAA Paper 2007-4314, 2007.

13. Tetlow, M.R., Doolan, C.J., "Comparison of Hydrogen and Hydrocarbon-Fueled Scramjet Engines for Orbital Insertion”, J. Spacecraft and Rockets Vol. 44,No. 2, 2007, pp. 365- 372.

14. Zambon, A.C. and Chelliah, H.K., "Explicit Reduced Reaction Models for Ignition, Flame Propagation, and Extinction of $\mathrm{C} 2 \mathrm{H} 4 / \mathrm{CH} 4 / \mathrm{H} 2$ and Air Systems", Combustion and Flame Vol. 150, 2007, pp. 71-91.

15. Heiser, W.H. and Pratt, D.T., Hypersonic Airbreathing Propulsion, AIAA Education Series, AIAA Pub., Washington DC, 1994.

16. Anderson, Jr., J.D., Hypersonics and High Temperature Gas Dynamics, McGraw-Hill Pub. NY, 1989. 
17. Hasselbrink, E.F. and Mungal, M.G., "Transverse Jets and Jet Flames: Part 1. Scaling Laws for Strong Transverse Jets", J. Fluid Mech. Vol. 443, 2001, pp.1-25.

18. Smith, S.H. and Mungal, M.G., "Mixing, Structure and Scaling of the Jet in Crossflow", J. Fluid Mech. 357, 1998, pp. 83-122.

19. Kuo, K.K., Principles of Combustion, Wiley and Sons Pub, NY, 2005.

20. Broadwell, J.E. and Breidenthal, R.E., "Structure and Mixing of a Transverse Jet in Incompressible Flow”, J. Fluid Mech. Vol. 148, 1984, pp. 405-412.

21. Huang, R.F. and Chang, J.M., "The Stability and Visualized Flame and Flow Structures of a Combusting Jet in Cross Flow". Combust. Flame Vol. 98, 1994, pp. 267-278.

22. Kalghatgi, G.T., "The Visible Shape and Size of a Turbulent Hydrocarbon Jet Diffusion Flame in a Cross-wind", Combust. Flame, Vol. 52, 1983, pp. 91-106.

23. Majeski, A.J., Wilson, D.J., Kostiuk, L.W. , "Predicting the Length of Low-momentum Jet Diffusion Flames in Crossflow", Combustion Science and Technology Vol. 176, No. 12, 2004, pp. 2001-2025.

24. Kostiuk, L.W., Majeski, A.J., Poudenx, P., "Scaling of Wake-stabilized Jet Diffusion Flames in a Transverse Air Stream", Proceedings of the Combustion Institute Vol. 28, 2000, pp. 553-559.

25. Gruber, M.R., Nejad, A.S., Chen, T.S., Dutton, J.C., "Compressibility Effects in Supersonic Transverse Injection Flowfields”, Phys. Fluids Vol. 9, No. 5, 1997, pp. 1448-1455.

26. Heister, S.D. and Karagozian, A.R., "Gaseous Jets in Supersonic Crossflow”, AIAA J. Vol. 28, 1990, pp. 819-827.

27. Driscoll. J.F., Huh, H., Yoon, Y., Donbar, J., "Measured Lengths of Supersonic Hydrogen Air Jet Flames - Compared to Subsonic Flame Lengths and Analysis", Combust. Flame Vol. 107, 1996, pp. 176-186.

28. Heiser, W.H. and Pratt, D.T., Progress in Aeronautics and Astronautics, Vol. 189, 2001, pp. 569- 581.

29. Billig, F.S., "Research on Supersonic Combustion", J. Propulsion and Power, Vol. 9, No. 4, 1993, pp. 499-504.

30. Billig, F.S., "Combustion Processes in Supersonic Flow", J. Propulsion and Power, Vol. 4, No. 3 , 1988, pp. 209-224.

31. Billig, F.S. and Dugger, G.L., "Predictions of Precombustion Wall Pressure Distributions in Scramjet Engines", J. Spacecraft and Rockets, Vol. 10, No. 9, 1973, pp. 620-622.

32. Billig, F.S. and Dugger, G.L., "The Interaction of Shock Waves and Heat Addition in the Design of Supersonic Combustors", Proc. Combust. Inst. Vol. 12, 1969, pp. 1125-1132.

33. Billig, F.S., "Proposed Supplement to Propulsion System Management Support Plan", JHU/APL report July $15,1986$.

34. Baurle, R.A. and Eklund, D.R., "Analysis of Dual-Mode Hydrocarbon Scramjet”, J. Propulsion and Power Vol.18, No. 5, 2002, pp. 990-1002.

35. Tam, C.J., Baurle, R.A., Gruber, M.R., "Numerical Study of Jet Injection into a Supersonic Crossflow", AIAA Paper 99-2254, 1999.

36. Sullins, G.A., "Demonstration of Mode Transition in a Scramjet Combustor", J. Propulsion and Power Vol. 9,No. 4, 1993, pp. 515-521.

37. Dessornes, O., "Tests of the JAPHAR Dual Mode Ramjet Engine”, Aerospace Science and Techol. Vol. 9, 2005, pp. 211-219.

38. Tam, C.J., Eklund ,D., Behdadnia, R. and Jackson, T., "Investigation of Boundary Layer Bleed for Improving Scramjet Isolator Performance”, AIAA Paper 2005-3286, 2005.

39. Nedungadi, A. and Van Wie, D.M., "Understanding Isolator Performance Operating in the Separated Shock Mode", AIAA Paper 2004-3832, 2004. 